\title{
O CENTENÁRIO DO TAYLORISMO E OS ESTUDOS SOBRE LIDERANÇA
}

\section{THE CENTENARY OF TAYLORISM AND LEADERSHIP STUDIES}

\begin{abstract}
Andréa Maruyama ${ }^{1}$
Carlos Pappini $\mathbf{J r}^{2}$ Maria Cristina S. Amorim ${ }^{3}$

\section{Resumo:}

Esse artigo revisita a centenária obra "Princípios da Administração Científica" escrita por Taylor no início do século XX. O objetivo é avaliar as contribuições de Taylor aos estudos sobre liderança, destacando a importância da leitura de uma obra seminal para o conhecimento em administração das organizações.
\end{abstract}

Palavras chaves: Taylor, teoria clássica da administração, administração científica, liderança.

\begin{abstract}
:
1 andreamaruyama@yahoo.com.br. Brasil, Mestranda em Administração pelo Programa de PósGraduação em Administração da Pontifícia Universidade Católica de São Paulo (PPGA/PUC-SP). Graduada em Administração Pública pela Universidade Estadual Paulista - Júlio de Mesquita Filho (UNESP), pós- graduação lato sensu em Gestão Empresarial pela Fundação Getúlio Vargas (FGV) e especialização em Formação de Coaching de Equipes pela FIA/USP. Rua Monte Alegre, 984. CEP: 05014901. São Paulo - SP - Brasil.

2 pappini@pappini.com.br. Brasil, Mestrando em Administração pelo Programa de Pós-Graduação em Administração da Pontifícia Universidade Católica de São Paulo (PPGA/PUC-SP). Graduado em Administração de Empresas pela Faculdade Campos Salles, Pós Graduação Latu Sensu em Marketing e MBA em Economia e Gestão em Saúde pela UNIFESP. Rua Monte Alegre, 984. CEP: 05014-901. São Paulo - SP - Brasil.

3 cris.amorim@pucsp.br. Brasil, Doutora em Ciências Sociais pelo Programa de Estudos PósGraduados em Ciências Sociais da Pontifícia Universidade Católica de São Paulo (PEPGCS/PUC-SP). Professora do Programa de Pós-Graduação em Administração da Pontifícia Universidade Católica de Sao Paulo (PPGA/PUC-SP). Rua Monte Alegre, 984. CEP: 05014-901. São Paulo - SP - Brasil.
\end{abstract}

Data da submissão: 22/08/2011

Data da aprovação: 05/09/2011

Revista Administração em Diálogo ISSN 2178-0080

Programa de Estudos Pós-Graduados em Administração Pontifícia Universidade Católica de São Paulo 
Main objective of this article is to review Mr. Taylor's publication " Principles of Scientific Management", a classic book written in the begging of XX century, based on contemporaneous demand related to leadership and management. His contribution for business is still part of organization management in XXI century which makes those principles deserve their focus kept but up dated.

Key words: Taylor, Scientific Management and Leadership

\section{Introdução}

O livro "Princípios da Administração Científica" de Frederick Winslow Taylor está completando seu primeiro centenário $(1911$ - 2011). Trata-se de obra considerada um marco nos estudos da administração como saber organizado, estabelecendo-se como a principal referência da teoria clássica da administração. Pelo alcance da obra torna-se relevante uma análise de sua estrutura e conceitos quando discutimos a literatura sobre liderança.

Para entender o ambiente trabalhado por Taylor, é necessário retomar a formação do pensamento administrativo simultaneamente à constituição da sociedade industrial. Assim como a doutrina do individualismo associado ao bem-estar coletivo presente na obra de Adam Smith (2003), as teses e contribuições da administração científica continuam presentes na operação de diversas instituições e atividades da sociedade, permanecendo como parâmetro para o aumento da produtividade o para o sucesso das organizações (publicas ou privadas, com ou sem fins lucrativos) (Chanlat, 2000). Na administração pública, os elementos "clássicos" podem inclusive ser apresentados como condição de modernização institucional, como o estudo de caso sobre o Tribunal de Contas da União, no qual foi realizado intenso esforço para a adoção do modelo gerencial, entenda-se, descrição estrita de funções, remuneração por desempenho, entre outros (Faro e outros 2010).

Ao longo da história, a consolidação do capitalismo iniciado no tocante às relações de trabalho dá-se na substituição das corporações de ofício pelo trabalho 
assalariado e a estruturação das unidades fabrís (MOTTA. VASCONCELOS, 2002). Encontra-se aí a matéria prima dos estudos sobre divisão de tarefas e adequação do trabalhador a cada função específica, proposta no século XX, por Taylor. O aumento da produtividade do trabalho decorrente da divisão do trabalho associado à inovação tecnológica e à expansão do mercado consumidor no século XIX gerou infinitas vezes mais riqueza do que os modelos anteriores reunidos. O capitalismo adota como núcleo de seu sucesso e atuação, a formação e o fortalecimento das empresas, o que afeta toda a sociedade e sua forma de produção e consumo (BAUER, 2008).

A reestruturação socioeconômica pertinente à economia industrial tornou premente a revisão e definição das relações de trabalho e, no foco do presente artigo, do papel dos líderes. A organização da produção baseada na divisão do trabalho e produção da mercadoria ${ }^{4}$ se deu não apenas no modus operandis, mas e principalmente, na busca contínua pelo incremento da produtividade. No inicio do século XX coube a Taylor formalizar a racionalização da produção industrial e do trabalho burocrático, esses últimos, os inevitáveis controles do trabalho fragmentado.

A recessão econômica de 1930 e as duas guerras mundiais do século XX produziram extraordinários efeitos políticos e sociais, entre eles, a ampliação da ação do Estado na constituição do "Estado do bem-estar" e na manutenção do crescimento econômico. Assim, o período entre 1950 e 1970 foi de expansão contínua do crescimento econômico, batizada como "era dourada" pelo historiador Eric Hobsbawn (2008). Porém, as crises econômicas dos anos 70 movido principalmente pela crise do petróleo, a reestruturação produtiva e a desregulamentação da economia nas décadas de 80 e 90 resultaram em aumento de instabilidade e acirramento da competição entre as organizações. A partir do início dos anos 90, os mercados se consolidam como globais e a busca de diferenciais de competitividade pressionam as organizações a ampliar a capacidade de adaptação. O título da obra de Marshal Berman (2007), “Tudo que é sólido

\footnotetext{
${ }^{4}$ Mercadoria define os bens e serviços com valor de troca e de uso, ou seja, produzida não para autoconsumo, mas para a troca.
} 
desmancha no ar", uma reflexão sobre a modernidade e alusão ao Manifesto Comunista de Marx e Engels, é uma ilustração adequada à instabilidade do período.

Relativamente à gestão das pessoas, o contexto do século XXI é marcado por várias contradições: de um lado, aumenta o grau de precariedade das condições de trabalho, de outro, a utilização da mão-de-obra (particularmente da parcela ultraqualificada) exige modelos crescentemente complexos, com foco no controle da subjetividade do indivíduo (HELOANI, 2007). O papel da liderança é re-significado, da ênfase ao gestor das transformações ao das redes e estruturas matriciais, do controlador de processos ao inspirador da inovação. Mudam as ênfases das recomendações ou definições das funções dos líderes, mas não se perdem as máximas de Taylor relativas ao exercício do poder, ainda que tal exercício, segundo Sennet (2007) seja crescentemente oculto.

O desenrolar da história econômica e social, bem como seus desdobramentos nos modelos de organização da produção não é um contínuo. Classificá-lo em fases agrícola, industrial ou do conhecimento, por exemplo, é mero recurso para ordenar a apresentação dos fenômenos. Na área da filosofia da ciência, que se ocupa em definir o que é ciência, a complexidade do campo de observação em que ela se dá e sua irredutibilidade a aspectos mensuráveis, pode ser datada, não sem arbitrariedade, desde a segunda metade do século XX. No campo da teoria da liderança, a emergência das estruturas matriciais acentua a prevalência das ações motivacionais. No entanto, os princípios tayloristas de indicadores mensuráveis de resultado nunca foram tão presentes quando está em foco a avaliação de desempenho, assim como a divisão de tarefas, hoje modernizada em "processos", como forma de maximizar a produtividade.

\section{O surgimento da administração como ciência e a obra de Taylor}

Os estudos sobre como organizar a atividade do trabalhador não têm como único e exclusivo iniciador Frederick Taylor. Motta (2003) destaca como os principais precursores, desde os estudos de Morelly, em o Código da Natureza que data 
aproximadamente de 1755, do Conde de Saint-Simon, O Organizador e O Sistema Industrial, de Robert Owen e seus estudos em New Lanark, na Escócia. Louis publicou em 1840 um livro intitulado Organização do Trabalho que serviu de inspiração para o conceito de cooperativa de produtores que consolidaria a migração do trabalhador rural individual para o produtor coletivo em busca da larga escala. Na lista dos contemporâneos da teoria clássica da administração encabeçada por Taylor, citamos ainda os estudos de Fayol, Gulick, Urwick, Gantt e Gilbreth.

Taylor elaborou os estudos "Notas sobre as Correias" em 1893 e "Gratificação por Peças" em 1895, pilares a sua obra maior. Outras publicações que precederam seu maior sucesso e o ajudaram na evolução do seu pensamento, foram a Administração de Oficinas de 1903, no qual chama a atenção para o papel da direção nas empresas e expressa as primeiras abordagens e preocupações sobre o papel das lideranças, e o livro técnico a “A Arte de Cortar Metais”. Em 1911, finalmente Taylor publica "Princípios da Administração Científica" que em poucos anos após o seu lançamento adquiriria fama mundial, sendo traduzido em diversas línguas (TAYLOR, 1999).

O fato de Taylor, além de pesquisador, ter sido um técnico e exercido a função de mestre de fábrica, permitiu que ele implantasse seus estudos sustentados no pensamento indutivo em consonância com a sua experiência adquirida, o que talvez justifique a maior adoção dos seus conceitos pelos gestores da época em detrimento aos outros pensadores. Sua visão prática e formação técnica de engenheiro encontraram também um ambiente favorável na academia que vivia sobre a base positivista. O determinismo como forma de gerar normatividade estava presente na prática da ciência da época, contribuindo de um lado, à maior aceitação dos princípios de divisão do trabalho propostas por Taylor, e de outro, estabelecendo uma chancela reducionista à sua obra que ainda o persegue e distorce seus conceitos.

Taylor inspira-se também no conceito da termodinâmica de N.Carnot, do qual retirou sua principal idéia da eficiência industrial com base na individualização da produtividade de cada trabalhador (Bauer, 2008). 
Os principais objetivos da obra de Taylor são:

a) Substituição do empirismo para uma denominada ciência do trabalho;

b) Busca da cooperação entre os trabalhadores;

c) Seleção do perfil correto de cada indivíduo para cada função específica;

d) Divisão de trabalho e responsabilidade entre a alta administração e os demais trabalhadores (Maximiano, 2008).

Ao considerar estes quatro objetivos, encontramos em todos eles e de forma mais evidenciada no item d, as relações entre a obra de Taylor e a liderança. Ao buscar estabelecer papéis e responsabilidades entre líder e liderados, Taylor segmenta e solidifica as definições de liderança, tão estudados quão inconclusivos pela literatura até os dias atuais. As críticas contundentes ao taylorismo acusam o autor de ilegítima racionalização do ser humano, transformado em recurso apenas econômico - homo economicus (Heloani, 2007). Não é nosso objetivo desqualificar a extensa crítica sobre o taylorismo, mas levantar a persistência das suas teses na teoria sobre liderança. Assim, vale a citação abaixo na qual Taylor afirma que o individuo é o principal diferencial das organizações, a despeito do crescimento dos processos como condição fundamental à produtividade.

“(...) no passado o homem estava em primeiro lugar; no futuro, o sistema terá a primazia. Isso, entretanto, não significa absolutamente, que os homens competentes não sejam necessários" (Taylor, 1999).

Admitir a importância dos "homens competentes" não significa obrigatoriamente melhorar as condições de trabalho e afrouxar controles. A contribuição teórica do taylorismo é a visão que o incremento da produtividade no trabalho, por conceito e aplicabilidade um tema universal e atemporal, resulte da eficiência do trabalho e não da maximização do esforço. Esse conceito foi aplicado por Taylor no estudo da divisão das tarefas e mais ainda no estudo sobre a eliminação da fadiga. Se avaliarmos esses 
princípios nas estruturas corporativas do século XXI, encontraremos uma situação pré Taylor no que diz respeito ao aumento da carga de trabalho sobre os indivíduos, condição básica para o aumento produtividade. Se a produtividade é sempre do trabalho, processos e tecnologias são instrumentos para ampliá-la por meio da maior intensidade do trabalho. E à liderança, cabe encontrar formas de obter aumento de produtividade, ainda que parcialmente negociada com os liderados, ou autocraticamente imposta.

\section{Teorias sobre liderança}

Embora o termo liderança venha sendo utilizado apenas há aproximadamente duzentos anos, Stogdill (1948) acredita que ele tenha aparecido por volta do ano 1.300 da era cristã. Podemos considerar ainda que a preocupação com a liderança seja tão antiga quanto a história escrita. A República de Platão constitui um bom exemplo dessas preocupações iniciais ao falar da adequada educação e treinamento dos líderes políticos (Bergamini, 1994: 24).

Fazendo um longo salto para o século $\mathrm{XX}$, os primeiros estudos sob a denominação de liderança ganharam mais visibilidade com a teoria de necessidades de Abraham Maslow nos anos 50 e tiveram origem nas raízes sociológicas do poder político e da burocracia institucional (Limongi-França. Arellano, 2002). De acordo com essa teoria, há no ser humano uma hierarquia de cinco categorias de necessidades. São elas: fisiológicas, segurança, social, estima e auto-realização. As necessidades fisiológicas e de segurança são descritas como necessidades de nível mais baixo e aquelas relacionadas à auto-realização são chamadas de nível mais alto (Robbins, 2002). Para motivar alguém é útil saber em que nível a pessoa se encontra no momento e colocar maior foco à satisfação daquele nível ou no patamar imediatamente superior (Robbins, 2002).

Nos anos de 1960 encontram-se um dos mais importantes estudos sobre tipos de liderança que se tornou referência para muitos administradores, o modelo proposto por McGregor com a Teoria X e a Teoria Y, no qual os valores do líder sobre as intenções de 
seus liderados determinariam um processo de influência mais autoritário (Teoria X) ou mais participativo (Teoria Y). (Hersey. Blanchard, 1986)

A teoria $X$ supõe que a maioria das pessoas prefere ser dirigida, não está interessada em assumir responsabilidades e deseja, acima de tudo, segurança. Essa filosofia é acompanhada pela crença de que as pessoas são motivadas pelo dinheiro, pelos benefícios marginais e pela ameaça de punição. A teoria Y supõe que as pessoas não são preguiçosas e irresponsáveis por natureza. Postula que os indivíduos podem autodirigirem-se e serem criativos no trabalho, se forem adequadamente motivados. Por isso, uma função essencial dos administradores é a de desencadear esse potencial nas pessoas. Uma pessoa corretamente motivada pode atingir melhor os seus próprios objetivos dirigindo seus esforços para a realização dos objetivos da empresa. (Hersey, Blanchard, 1986: 61).

Em 1969, Paul Hersey, da Universidade de Ohio e Kenneth H. Blanchard, da Universidade de Massachusetts, na histórica obra "Psicologia para administradores de Empresas", sintetizaram dezenas de estudos que incluem desde categorias de administração científica de Taylor até ensaios de Hawtorne sobre moral dos empregados, estilos de supervisão e resultados de produtividade, nível de maturidade/imaturidade dos liderados, atuação da liderança, liderança situacional e estrutura dos grupos (LimongiFrança. Arellano, 2002). Desde então, é possível ao se percorrer a grande quantidade de estudos e teorias sobre liderança, descobrir que, embora todos eles falem a respeito de um mesmo assunto, cada um tenha destacado um aspecto diferente a respeito do contexto e do processo.

Em "Liderança, administração do sentido", Bergamini (1994) relaciona mais um elenco de diferentes pontos de vista, que transcrevemos aqui para ilustrar as definições no decorrer dos anos. 
1. Liderança é o comportamento de um indivíduo quando está dirigindo as atividades de um grupo em direção a um objetivo comum (Hemphill e Coons, 1957: 7).

2. Liderança é um tipo especial de relacionamento de poder caracterizado pela percepção dos membros do grupo no sentido de que outro membro do grupo tem o direito de prescrever padrões de comportamento na posição daquele que dirige, enquanto a sua atividade na qualidade de membro do grupo (Janda, 1960: 35).

3. Liderança é influência pessoal, exercida em uma situação e dirigida através do processo de comunicação, no sentido de um objetivo especifico (Tannenbaum. Weschler. Massarik, 1961: 24).

4. Liderança é uma interação entre pessoas na qual uma apresenta informação de um tipo e de tal maneira que os outros se tornam convencidos de que seus resultados serão melhorados caso comportem-se da maneira sugerida ou desejada (Jacobs, 1970: 232).

5. Liderança é o início e a manutenção da estrutura em termos de expectativa e interação (Stogdill, 1974: 411).

6. Liderança é o incremento da influência sobre e acima de uma submissão mecânica com as diretrizes rotineiras da organização (Katz. Kahn, 1978: 528). 
7. Liderança é o processo de influenciar as atividades de um grupo organizado na direção da realização de um objetivo. (Rouch. Behling, 1984: 46)”. (Bergamini, 1994: 14).

Além destas, vale destacar a definição de Hersey e Blanchard (1986), que definem liderança como o processo de influenciar as atividades de indivíduos ou grupos para a consecução de um objetivo em uma dada situação. Em essência, envolve a realização de objetivos com e por meio das pessoas. Conseqüentemente, um líder precisa preocupar-se com tarefas e relações humanas. E essas preocupações da liderança refletem duas das primeiras escolas de teoria organizacional: administração científica e relações humanas. (Hersey. Blanchard, 1986: 105). Para os autores, na teoria da administração científica ou clássica, a melhor maneira de aumentar a produção era melhorar as técnicas ou métodos utilizados pelos trabalhadores.

Na obra de Bergamini, a autora parte do pressuposto de que liderar é, antes de qualquer coisa, ser capaz de administrar o sentido que as pessoas dão àquilo que estão fazendo. Essa administração do sentido implica o conhecimento e domínio das características da cultura da organização, ao mesmo tempo em que liderar exige também o conhecimento do sentido que cada um dá à atividade que desempenha. (Bergamini, 1994: 22). Para Vergara (1999), administradora e pedagoga, a liderança está associada a estímulos e incentivos que podem motivar as pessoas para a realização da missão, da visão e dos objetivos empresariais. E como funções importantes do líder, a autora aponta perscrutar o ambiente externo, estando atento a mudanças; contribuir para a formação de valores e crenças organizacionais dignificantes para satisfação das pessoas; e ser hábil em esclarecer problemas.

Em Robbins (2002), liderança é a capacidade de influenciar um grupo em direção ao alcance de objetivos e a origem dessa influência deve ser formal, como a conferida por um alto cargo na organização. E como essas posições subentendem certo grau de 
autoridade, uma pessoa pode assumir um papel de liderança apenas em função do cargo que ocupa.

Sem a pretensão de exaurir a revisão sobre a teoria da liderança, mas objetivando destacar a ausência de consenso, concluímos termos, então, vários estudos de como identificar, selecionar, preparar, desenvolver, aperfeiçoar, reconhecer e direcionar este indivíduo intitulado líder pelo grupo ou pela sociedade, por seu cargo, recursos, projeto, poder e/ou autoridade para que se torne, exerça e mantenha o exercício de sua liderança.

\section{A obra de Taylor e as contribuições para a liderança}

A obra de Taylor "Princípios de Administração Científica", após cem anos de sua publicação nos remete à reflexão de como foi fértil a sua época ao organizar o saber sobre a administração, apresentar sistemas de controle da produtividade e levantar os aspectos relativos à tema de nosso interesse, a liderança.

No primeiro aspecto, a obra dá conta das definições de eficiência, qualidade, organização e método, divisão de trabalho, aperfeiçoamento de réguas de cálculo, padronização de instrumentos, estudo do tempo e movimento, planejamento do serviço, segurança no trabalho e vantagens do processo econômico. A melhor maneira de aumentar a produção era melhorar as técnicas ou métodos usados pelos trabalhadores. $\mathrm{E}$ para realizar esse plano, Taylor iniciou estudos de tempo e movimento para analisar tarefas de trabalho, visando melhorar o desempenho em todos os aspectos da organização (Hersey. Blanchard, 1986: 106).

"Taylor foi o primeiro autor a sistematizar um modelo de administração, entendendo-se como tal um sistema de idéias ou doutrinas aliadas a técnicas ou ferramentas. Para Taylor, a administração científica era uma revolução mental, uma revolução na maneira de encarar o trabalho e as responsabilidades em relação à empresa e aos colegas" (Maximiano, 2008: 157).

Revista Administração em Diálogo ISSN 2178-0080 
Estes aspectos foram a marca da administração científica no campo dos estudos organizacionais. Representaram a passagem de um sistema baseado na manufatura, na produção artesanal, na relação de mestre de ofício e aprendiz multi-tarefas para um novo sistema de produção: em massa, com ênfase na produtividade, divisão de tarefas entre os operários para melhor especialização e eficiência, concentração de conhecimento e planejamento na gerência, agora com maiores e novas atribuições. No campo ideológico, a administração científica de base taylorista incentivou a identidade de interesse entre empregadores e empregados em busca de benefícios econômicos.

"Sob o sistema antigo de administração, o bom êxito depende quase inteiramente de obter a iniciativa do operário e raramente esta iniciativa é alcançada. $\mathrm{Na}$ administração científica, a iniciativa do trabalhador (que é seu esforço, sua boa vontade, seu engenho) é obtida com absoluta uniformidade e em grau muito maior do que é possível sob o antigo sistema; e em acréscimo a esta vantagem referente ao homem, os gerentes assumem novos encargos e responsabilidades, jamais imaginados no passado. À gerência é atribuída, por exemplo, a função de reunir todos os conhecimentos tradicionais que no passado possuíram os trabalhadores e então, classificá-los, tabulá-los, reduzí-los a normas, leis ou fórmulas, grandemente úteis ao operário para execução do seu trabalho diário. Além de desenvolver deste modo uma ciência, a direção exerce três tipos de atribuições que envolvem novos e pesados encargos para ela" (Taylor, 1999: 40).

Os fundamentos de administração científica também trouxeram avanços e inovações aos estudos e práticas de liderança e desenvolvimento de pessoas. Nesse campo, a obra abordou temas como identidade de interesses de empregados e empregadores, seleção de homens eficientes, influência da produção na prosperidade, causas da vadiagem no trabalho, fadiga, efeitos sobre a moral dos trabalhadores, benefícios resultantes para os empregados e empregadores, elevação de salários, necessidade de assistência ao trabalhador, atitude mental e psicologia dos trabalhadores, supervisores, cooperação, além de distribuição dos benefícios. Novas atitudes e responsabilidades foram atribuídas aos gerentes, responsáveis pelo desenvolvimento de 
um método de trabalho para cada função, seleção e treinamento, instituir relações de cooperação para melhor articulação do trabalho e proporcionar divisão de tarefas e responsabilidades mais equitativa entre os trabalhadores para que não fiquem sobrecarregados.

Para Taylor, a combinação da iniciativa do trabalhador com os novos tipos de atribuições conferidas à direção faz a administração mais eficiente do que os antigos sistemas (TAYLOR, 1999). À luz dos estudos sobre liderança é possível identificar em Taylor os elementos caros às primeiras, tais como estruturação de processos e suas implicações nas relações humanas; como motivação; reconhecimento do trabalho; acompanhamento individual e desenvolvimento de habilidades; direcionamento e atuação como facilitador das relações com os trabalhadores.

No capítulo exclusivo para discutir a posição dos supervisores e o papel da gerência, Taylor (1999) faz menção a princípios conhecidos pelos estudiosos de liderança que foram inovadores a sua época. Entre esses princípios, destacamos o reconhecimento da importância do trabalho dos gestores como influenciadores de atitudes, organizadores de tarefas e responsabilidades; dos ganhos de autonomia para decisões e ações, além de instigar a necessidade de maior capacitação pessoal e preparo diferenciado para lidar com maiores responsabilidades e assuntos como planejamento e distribuição de benefícios.

"Estes homens têm necessidade de passar a maior parte de seu tempo na seção de planejamento, porque devem estar ao lado dos registros e dados que continuamente usam em seu trabalho e porque este trabalho requer tranqüilidade de ação" (TAYLOR, 1999: 90).

Em 1986, Hersey e Blanchard lançaram o conceito de liderança situacional. De acordo com os autores, o estilo de liderança que uma pessoa deve adotar com indivíduos ou grupos depende do nível de maturidade das pessoas que o líder deseja influenciar (Hersey. Blanchard, 1986: 188), conceito este que também encontramos em Taylor ao 
descrever a ação diferenciada dos gerentes quando do tratamento de trabalhadores experientes ou aprendizes.

Os autores definem liderança como o processo de influenciar as atividades de indivíduos ou grupos para a consecução de um objetivo em uma dada situação. Alinhados à expectativa de liderança para inovação que, nos limites desse artigo, envolve a realização de objetivos com e por meio das pessoas, os autores reforçam a necessidade do líder em preocupar-se com tarefas e relações humanas, essencial para a utilização de criatividade como recurso de produção (Hersey. Blanchard, 1986). Em Taylor também encontramos afinidades com este contemporâneo conceito.

"Não se deve esquecer de que acima de toda essa organização deve estar um chefe otimista, enérgico e esforçado que saiba tão pacientemente esperar quanto trabalhar" (TAYLOR, 1999: 67). E ainda: "Sendo cada um escolhido por seus conhecimentos e habilidade pessoal na especialidade, é capaz não somente de dizer o que deve fazer o trabalhador, mas também, no caso de necessidade, executar o serviço na frente do operário, de modo que lhe exemplifique o melhor método de realizar o trabalho" (TAYLOR, 1999: 91).

No tocante à inovação, o conhecimento é por vezes, considerado um insumo de produção. Assim, com base na teoria das inteligências múltiplas, a criatividade é a base para inovação, e cabe ao líder incentivar em seus liderados o questionamento, observação, experimentação e trabalho em rede (Christensen. Gregersen, 2009). Foge ao objetivo do artigo estender a discussão sobre conhecimento como insumo de produção, porém, interessa-nos ressaltar que o papel do líder junto à promoção da criatividade não é estranho às contribuições de Taylor.

\section{Considerações finais}

$\mathrm{Na}$ perspectiva escolhida, as contribuições teóricas no campo da administração das organizações espelham as transformações de suas épocas. Adam Smith, no século 
XVII, relatou a divisão do trabalho que presenciou em uma fábrica de alfinetes, e foi visionário ao compreender a importância extrema da industrialização nascente como "causa da riqueza das nações", título de sua obra (Smith, 2003). Taylor foi observador lúcido de seu tempo, o início de século $\mathrm{XX}$, visionário ao compreender a papel determinante do controle dos tempos e métodos para o aumento da produtividade, base da expansão da riqueza das organizações. Seu modelo pretendia-se completo, tratou também das singularidades da gestão de pessoas pelos gerentes (ou gestores, como seriam chamados mais tarde). Suas premissas marcaram os trabalhos dos estudiosos posteriores, inclusive no campo das teorias sobre liderança. As contribuições pós-taylor são indiscutivelmente valiosas, mas compreender suas origens em um autor como Taylor ajuda avaliá-las e utilizá-las melhor.

As muitas definições de liderança, parte das quais apresentamos aproveitando-nos da síntese organizada por Bergamini (1994), usam recorrentemente do verbo influenciar para designar a relação entre líderes e liderados. De um lado, o verbo retrata a compreensão dos limites do poder dos primeiros sobre os segundos, de outro, nubla as funções de controlar, vigiar e punir da tradição foucaultiana (FOUCAULT, 2008) mais claras na obra de Taylor - como se as organizações do século XXI renunciassem a elas.

O conhecimento, assim como a história, não é caracterizado pelo avanço e incorporação contínuos de "novos" saberes, o saber produzido recentemente não nos isenta em, todos os casos, de estudar autores de tempos passados. Taylor é um autor que vale ser revisitado em nome, no mínimo, do apreço pela ampliação da cultura do leitor.

\section{Referências}

AMORIM, M.C.S.; FREDERICO, R. Criatividade, inovação e controle nas organizações. XXXII ENANPAD, 2008.

AMORIM, M. C. S.; MARTINS, R. H. P. Poder e liderança, as contribuições de Maquiavel, Gramsci, Hayeck e Foulcault. In: XXXI ENANPAD, 2007, Rio de Janeiro. XXXI ENANPAD. Rio de Janeiro: ANPAD, 2007. 
BAUER, R. Gestão da Mudança - Caos e Complexidade nas Organizações. São Paulo: Editora Atlas, 2008.

BERGAMINI, C. W. Liderança - administração do sentido. $3^{\text {a }}$ tiragem, SP: Atlas, 1994.

BERMAN, Marshall. Tudo que é sólido desmancha no ar - São Paulo: Cia das Letras, 2007.

CHANLAT, J.F. Ciências Sociais e Management. São Paulo: Editora Atlas, 2000.

CHIAVENATO, I. Introdução à teoria geral da administração. $6^{\mathbf{a}}$ ed. Rio de Janeiro: Elsevier, 2000.

CLEMENTE, R., Resenha: Prophet of innovation: Joseph Schumpeter and creative destruction. Revista Brasileira de Inovação, Rio de Janeiro, 7(1), p.243-250, 2008.

DI SERIO, L.C.; VASCONCELOS, M.A., Estratégia e Competitividade Empresarial: Inovação e criação de valor. 1 ${ }^{a}$. Edição. São Paulo: Editora Saraiva, 2009.

DYER, J.H.; CHRISTENSEN, C.M.; GREGERSEN,H.B., The Innovator's DNA. Harvard Business Review, p.1-9. Dez./ 2009.

FARO, E. ; AMORIM, Maria Cristina Sanches ; TREVISAN, L. ; JUNQUEIRA, L. P. . Âncoras de carreira e transformações no modelo de administração: estudo de caso do Tribunal de Contas da União (TCU). Cadernos EBAPE.BR (FGV), v. 2, p. 34-67, 2010.

FOUCAULT, Michel. Microfísica do poder. São Paulo: Graal Editora, 2008.

FREDERICO, R., Criatividade e Inovação nas organizações, uma crítica a literatura do management pela abordagem político-econômica. Dissertação Mestrado em Administração, Pontifícia Universidade de Católica de São Paulo (PUC/SP), 2008.

HARVARD BUSINESS REVIEW, O Valor da Inovação. $1^{\text {a }}$. Edição. São Paulo: Editora Campus, 2005.

HELOANI, R. Gestão e Organização no Capitalismo Globalizado. São Paulo: Editora Atlas, 2007.

HERSEY, P. BLANCHARD, K. Psicologia para administradores - a teoria e as técnicas da liderança situacional. SP: EPU, 1986.

HOBSBAWN, J. E. Era dos Extremos- O Breve Século XX, São Paulo: Cia das Letras 2008.

KELLEY, T. The Ten Faces of Innovation, IDEO's strategies for beating the devil's advocate \& driving creativity throughout your organization. $1^{\text {st }}$ Edition. New York: Doubleday, 2005.

KOUZES, J. POSNER, B. P. O desafio da liderança. $3^{\text {a }}$ ed. Rio: Campus, 2003. 
LIMONGI-FRANÇA e ARELLANO. Ana C. e Eliete B. Liderança, poder e comportamento organizacional. IN: FLEURY, Maria T. Leme (org.) As pessoas na Organização. Ed. Gente, SP 2002, p.259-269.

MAQUIAVEL, N. O Príncipe. 2a ed. SP: Martins Fontes, 1996.

MAXIMINIANO, A.C.A. Teoria Geral da Administração. São Paulo: Editora Atlas, 2008.

MC CRAW, T.K., Prophet of Innovation: Joseph Schumpeter and Creative Destruction. Cambridge, Mass.: The Belknap of Harvard University Press, 2007.

MOTTA, F.C.P. Teoria das Organizações - Evolução e Crítica. São Paulo: Editora Pioneira Thomson Learning, 2003.

MOTTA, F.C.P. e VASCONCELOS, I.F.G. Teoria Geral da Administração. São Paulo: Editora Pioneira Thomson Learning, 2002.

ROBBINS, S. P. Comportamento Organizacional. SP: Prentice Hall, 2002.

SCHUMPETER, J.A., Teoria do Desenvolvimento Econômico (Os Economistas). São Paulo: Editora Nova Cultural, 1997.

SENNET, Richard. A corrosão do caráter. São Paulo: Cia das Letras, 2007.

SMITH, A., A Riqueza das Nações. São Paulo: Editora Martins Fontes, 2003.

STOGDILL, R. M. Personal Factors associated with leadership: a survey of the literature. Journal of Psychology, 25, p. 37-71, 1948.

TAYLOR, F.W. Princípios de Administração Científica. São Paulo: Editora Atlas, 1999.

VERGARA, S. C. Gestão de pessoas. São Paulo: Atlas, 1999.

Revista Administração em Diálogo ISSN 2178-0080 